\title{
Linguistic and cultural assimilation of borrowing in the Russian language: case study of sinicisms
}

\begin{abstract}
The article is devoted to the issues that have become especially relevant at the present time; they are connected with the problem of lexical borrowing. Recently, borrowings from the Chinese language have intensified in the Russian language due to the wider cultural, economic, and political ties between Russia and China. The words borrowed from the Chinese language have a different degree of assimilation in Russian: the word "book" has the highest degree, while words "lychee" and "mango" the lowest. The meaning of the borrowed word develops in time, though the object of nomination should be in demand in different spheres of life. The development of meaning includes the acquisition of figurative meanings, connotations, desemantization, which allows the use of the borrowing as an onym and the inclusion of a foreign word in paremia.
\end{abstract}

Volume 3 Issue I - 2019

\author{
Olga Kasymova, Gong Lei \\ Doctor of Philology, Bashkir State University, Russia
}

Correspondence: Olga Kasymova, Doctor of Philology,

Bashkir State University, Russia, Email olgakasymova@yandex.ru

Received: December 31, 2018 | Published: February 25, 2019

Keywords: borrowings, Russian, Chinese, sinicism, semantics

\section{Introduction}

One of the most important language functions is nominative. The need to name the increasing number of new phenomena leads to new words in the language created by means of the word-formation capabilities of the language system or by borrowing. Along with the development of international and intercultural communication in the modern world, the new borrowed words have enriched both the knowledge about the world around the people and their linguistic view of the world. Borrowings are not only part of the vocabulary of the national language but also the "conductors" of the new cultural elements. The new prospects of the international relations between Russia and China in the $21^{\text {st }}$ century make preconditions for widening the mutual borrowings from Russian to Chinese and vice versa. China and Russia share a long border $(4,209.3 \mathrm{~km})$ and constantly influence each other in all spheres of life. The relations between China and Russia have gone through various stages. The mid-17th century to the 1st quarter of the 20 century was the time of the collaborative reclamation of the Northern and North-Eastern China. The period of 1945-1956 was the time of friendship, while from the late 1950's to the late 80 's, the countries were openly hostile to each other. In the 21 st century, the relations between the two entered a new stage of development: the one with mutual economic benefit and integration. Language, as a most important medium to connect different nations and cultures, plays a crucial role in this process. At the same time, the mutual penetration of lexical units from the languages of the two neighboring states is inevitable. It points to the mutual cultural diffusion of these nations. The multi-structured languages (isolating Chinese and flexional Russian) have insignificant number of mutual borrowings. Despite the fact that the Chinese and Russians have lived in close proximity for a long time, lexical borrowings are limited. According to researchers, the Russian language contains 20 to 40 words of the Chinese origin. ${ }^{1}$ Some researchers count 90 words of the Chinese origin in Russian. ${ }^{2}$

\section{Methodology}

For the study of borrowings from the Chinese language into Russian, we have selected data from dictionaries of various types: explanatory, encyclopedic, associative, etymological, dictionaries of new words and expressions, word-formative and foreign words dictionaries. We have examined 45 Sinicisms used in the speech of Russian people. This usage was traced in the National Corpus of the Russian Language in as many as 46,165 examples. Among the words borrowed from the Chinese language, we have included everything possible, including the rarely used lexemes as well as terms and highly specialized vocabulary. We have determined the frequency of word usage with due respect to how often it is reflected in the dictionaries of the Russian language. The neologisms that are not reflected in the dictionaries were checked according to the National Corpus of the Russian Language. The words not registered as used by the Russian speakers were not considered borrowings. Methods such as the component analysis of the word meaning, contrastive and comparative historical analysis, as well as translation and interpretation techniques were used in this study. The main methods are system descriptive and contrastive. The system descriptive method was used during the selection and classification of the material, while contrastive was employed to establish the interlanguage relationships between the lexical units. This methodology allowed a wide-range analysis of the main aspects lexical interaction between the Russian and Chinese languages. The analysis of the borrowings from the Chinese into the Russian language was facilitated by the method of corpus linguistics, which allowed seeing the process of assimilating the Chinese language by the Russian language consciousness in numerous examples. All of these methods serve to confirm the main conclusions to which we arrived at in the course of the study. The units from the Chinese language borrowed due to social reasons develop according to the internal language rules of the Russian language. The degree of the assimilation of the Chinese borrowings depends on a number of cultural, linguistic, and social factors; primarily on how long the lexeme existed in the host language and how often the denotation is used in the different spheres of life. The chosen research methods allowed distributing the borrowings according to the degree of their assimilation in the Russian language.

\section{Phonetic and graphic assimilation of sinicisms}

In any language, the classification of borrowed words consists of two parts: the borrowing while retaining (to some extent) the phonetic or other features of the original language and the borrowing 
of a meaning (translated borrowed word). The former (the words with preserved phonetic features of the source language) contains the combinations of sounds unusual for the receiving language, although they cannot preserve their pronunciation completely since the articulation of sounds has to comply with the rules of the language; otherwise, it will be an out-of-system foreign-language word. Sinicisms are included in the language system through the adapted phonetic inclusion. The phonetically non-assimilated vocabulary in the Russian language is not pronounced in accordance with the laws of the Russian orthoepy. What we mean is the degree of the phonetic assimilation of the borrowing, which in some cases is low. These are the Sinicisms containing the combinations of sounds atypical for the Russian language: Chow-Chow, Putonghua, Tao, Pu-erh, or yuan.

The analysis of the stages and features of structural and semantic adaptation of borrowings from the Chinese into Russian shows that the stabilization of pronunciation and spelling is characteristic of most words. The process of phonetic adaptation is the one all the words undergo, but some borrowings-neologisms display inherent instability of spelling (e.g., in Russian kunfu, kung-fu, kungfu). In this case, there is not always a direct correlation between the time of borrowing and the adopted graphic form. Thus, the word kunfu / kung-fu/kungfu is found in the National Corpus of the Russian Language since 1997; yang/yan since 1998; FengShui/Feng Shui since 2001, ulun/Oolong was recorded in 2007; buuzy/buzy/pozy/buzy-pozy is not recorded in the National Corpus of the Russian Language but found in cooking web-sites. The word kung-fu is used quite actively since it became widely known due to a movie: a full-length animated film Kung Fu Panda was released in 2008. This martial art is widely presented in the films of Jackie Chan. Nevertheless, over the twenty years of its active usage, the generally accepted version of the word has not been developed. The word yang/yan as one of the notions in Chinese philosophy was extremely popular in the 1990s; a popular music group Yin-Yang exists too, but the spelling of this Sinicism is not yet established in Russian. Later, in the 21st century, other words with graphic variations have been registered in the National Corpus of the Russian Language (FengShui/Feng Shui; ulun/Oolong; buuzy/buzy/ pozy/buzy-pozy). They are less popular, and their graphic unambiguity is not regulated because they are not registered in dictionaries.

\section{Thematic groups of borrowings from Chinese}

According to Dobrodomov $\mathrm{IG}^{3}$, a borrowing is "an element of a foreign language (word, morpheme, syntactic structure, etc.) transferred from one language to another as a result of language contacts, as well as the process of transition of elements from one language to another" (pp. 158-159). Unlike Slavic, Germanic, and Romance languages, Chinese as a donor language does not play a significant role in filling the Russian language with vocabulary Recently, English as a single source language has been actively used. Nevertheless, there are a certain number of borrowings from the Chinese language, which make up several thematic groups, and their composition is being replenished. Lexical borrowings from Chinese into Russian are limited in various linguistic and socio-cultural ways. The borrowed words display different degrees of assimilation in grammar and function.

They comprise eight thematic groups, each with one or more common seme. The first group is made up of the names of plants (orange, badian, kaoliang, ginseng, kumquat, lychee, mango, tea, chumiza (millet)). The second group is product names (orange, tea, buzy/pozy, ketchup, lychee, mango, manty dumplings, tofu, funchoza cellophane noodles, tea, puer, oolong). The third group includes household items (wok, junk, pearls, book, satin, fanza, shantung, yuan). The fourth group consists of philosophical and religious concepts (Tao, Zen, Yin, Confucius, Feng Shui, Yang/Yang). The fifth group is the names of games and sports (kungfu, Mahjong, wushu, qigong). The sixth group is the names of animals (Panda, ChowChow, Shar-Pei, Shih Tzu). The small group consists of the names of the suppoters of political views and the participants of historical events (red guard (khunveibin), Tai-ping). Linguistic phenomena borrowed from Chinese are also partially represented in Russian (Putonghua, Pinyin).

Although there are few borrowed words from the Chinese language, they reflect changes both in the tangible sphere of the Russian linguistic view of the world and in the mental one. In the Chinese language, there is an idiom Sparrow is small, Complete, which means "Although sparrow is very small, it has all the internals like all the other big birds." This expression uncovers the role of the words borrowed from the Chinese language in the Russian language: although they are few, they have an impact on the Russian language and hold a prominent place in the Russian linguistic culture. Despite the small number of words included in the Russian language from Chinese, the history of these borrowings dates back to the early middle ages. The first borrowings were the words book and pearls. The word book is indirectly borrowed from Chinese through the ancient Turkic language. In Vasmer's ${ }^{4}$ etymological dictionary the word is listed as borrowed from proto-Slavic *kniga through the Old Turkic language rising to the Chinese $k$ ' $\Omega$ üen (scroll) (pp. 262-263). According to the dictionary of Shansky NM, ${ }^{5}$ the word pearl (Rus. zhemchug) is borrowed in the $12^{\text {th }}$ century from the Turkic language where it is the renewal of Chinese pearl pronounced zhēn zhū, gonchu, representing the addition of two words: gon (real) and chu (pearl). The Old Russian Dictionary shows its spelling as ZHEMCHOUG and ZHENCHOUG. The confirmation of this period of borrowing are the phonetic features of medieval Chinese, namely the fact that in the early middle ages, the final $-m$ still existed, but it gradually merged with the ending- $n$ in words and later ceased to be used. In addition, at this time, a short tone that ended in -p,-t,-k as a closed syllable still existed in the Chinese language, and after the $13^{\text {th }}$ century only, it disappeared and moved to the other tones. The word pearl shows both these features: zhem(Jane) ends in -m, while -chug (Bead) is a short tone with a-k. This means that the word had already been borrowed by the time these phonetic phenomena in medieval Chinese ceased to exist; therefore, the borrowing into Russia still retains its original pronunciation.

In the National Corpus of the Russian Language, the first recorded borrowings from the Chinese language date back to 1728, and the registered word is tea (Rus. chai). Officially, tea appeared in Russia in 1638, when Russian Ambassador Vasily Starkov brought it as a gift from the Western Mongolian Altyn Khan. However, Siberians drank tea long before Starkov's mission; this product was brought from Mongolia in the $16^{\text {th }}$ century. The earliest use of the word orange (Rus. apelsin) recorded in the National Corpus of the Russian Language dates back to 1811. Orange was brought by the Portuguese from China to Europe in the $15-16^{\text {th }}$ centuries. This is an indirect borrowing and a hybrid word: the Chinese part is the second syllabus (-sin), which comes from the name of the ancient Chinese dynasty Qin qín, symbolizing China in many languages. Most of the studied Chinese words were borrowed recently: in the $20-21^{\text {st }}$ centuries. According to the researchers of borrowings from Chinese into Russian, "almost $50 \%$ of the words were included in the dictionaries of foreign words that appeared in the first decade of the $21^{\text {st }}$ century". ${ }^{2}$ These words can be referred to a group of "common theme neologisms," for example, wok guo, kumquat jinju, lychee lizhi, pozy baozi, fenshui fengshui". ${ }^{1}$ 


\section{Semantic assimilation of the words borrowed from the Chinese language}

Most often, the borrowing occurs at the lexical level. For the languages of different structures, such as Chinese and Russian, this is the only possible way of interaction. The Russian words borrowed in the Chinese vocabulary were studied in different ways in the works of Oglezneva EA, ${ }^{6}$ The assimilation of borrowings from Chinese into Russian is a complex process whereby semantic properties get assimilated by modifying the original meaning through the formation of derived meanings and words as well as the development of associative links. In Russian, there are borrowings from the Chinese language fully assimilated by the language system (orange, pearl, book, satin, and tea). Other Sinicisms are only partially assimilated and used sparingly. From the point of view of semantic assimilation, Sinicisms are divided into two groups: those with developed derivative meanings and those that represent a particular borrowed phenomenon. Let us address the word zhemchug (pearl) as an example of the semantic assimilation of the meaning and the use of the word. It's meaning in the "Explanatory Dictionary of the Russian Language" by Ozhegov $\mathrm{SN}^{7}$ ' is given as an unambiguous one ('solid, consisting mainly of mother-of-pearl formation in bivalve shells of molluscs'); the definition also highlights the development of metonymy (pearls, pearls=necklace) and metaphors (about the whiteness of teeth) ( $p$. 191). By analysing the dictionary data, it can be argued that this word is well-assimilated in the Russian language: it has all the grammatical categories inherent in a noun; and there are derived meanings.

The long-term semantic development of the word pearls expanded its use in the Russian language. The spread of pearls and jewelry made of it in household made its properties (size and form) well-recognized in the collective memory, and its color (pearl) is representative. The analysis of the use of the word pearl in the National Corpus of the Russian Language proves that the figurative meaning 'jewelry' occurs most often: Pearl was the first of the precious jewelry known to people (V. V. Ovchinnikov). The degree of adaptation of the word is evidenced by the expansion of its meaning. The figurative meaning (straight teeth) is found in many examples in the Corpus: Pink lips slightly ajar revealed wet pearls of teeth (Yevgeny Lukin). The comparison of pearls with drops of water, liquid or frozen (rain, dew, hail), as well as with tears and the use of words calling these concepts in the same context is also relevant: Pearls of dewdrop around (Vasily Golovanov). In the $19^{\text {th }}$ century, the connection between 'pearls' and poetry/words was not uncommon. For example:...Pushkin's poems are pearls scattered on velvet (V. G. Belinsky). The word pearl is also used to refer to other abstract concepts: art, health, thought, humility, etc.: Pearls of humility, pearls of knowledge, black pearls of prison impressions. The word pearl can be used to refer to sounds (birds singing): In the neighbouring oak forests outside the city gates, nightingales scattered pearls of their voices all night (A. P. Ladinsky).

Pearl converges in the Russian language consciousness also with cereals and flowers:... rice to rice, while each is by itself. Pearls indeed! (Alla Kostina); Lily-of-the-Valley is now like a golden web of pearls (O.A. Bessarabova). In our minds, the word pearl has a positive connotation that allows us to use it for a positive assessment of something. Meanwhile, the connotation of "excellent" becomes the center of lexical meaning: Every word of his is a pearl! (S. Annensky). Desemantization as a result of the development of the word meaning leads to the complete loss of its connection with the main meaning and the reference - a solid, rounded formation extracted from the shells of mollusks. For example: cruiser "Pearl", toothpaste "Pearl" scrub "Black Pearl"; rocambole "Pearl."Thus, in the Russian language, the structure of the polysemantic word pearl has developed significantly and began to include five lexical and semantic variants with radial organization. The second meaning is formed by the method of metonymic transfer; the third, fourth, and fifth meanings are formed by means of the metaphorical transfer from the first one. Their relationship can be shown as follows (Table 1). Marinova EV, ${ }^{8}$ believes that "the process of formation of a new phraseological unit on the basis of foreign neologism deserves special study. By itself, this fact indicates the entry of new foreign words in the language system, and, obviously, it can be regarded as a criterion of the assimilation of the foreign-language words" (p. 4). The word pearl borrowed from the Chinese language has this criterion: it is used in the proverb "some have soup not thick, others have pearls not big" and its colloquial versions:... someone's soup liquid, and someone's pearls small (Alexander Semenov).

Table I Structure of lexico-semantic variants of the word pearls

\begin{tabular}{lll}
\hline & \multicolumn{2}{l}{ Rounded formation extracted from shells of mollusks } \\
\hline Jewelry & Teeth $\quad$ Nucleus of abstract concepts $\quad$ Small round object
\end{tabular}

Thus, the word pearl is semantically and grammatically assimilated by the Russian language. It has the main and additional metonymic and metaphorical meanings. It also has derivatived meanings not registered in dictionaries. For example, it is used for naming liquid and solid water objects (rain, hail). Positive connotative meaning of the word pearl is manifested in the expressions of approval. There is also a proverb with this word. A special case of the development of the word meaning is desemantization of pearls. Lexical-semantic adaptation of Sinicisms is connected to how frequently the word is used by Russian native speakers and how long it exists in the language, as it takes centuries to form a generalized linguistic consciousness. Fully assimilated are words such as book, pearl, orange and tea. They have a developed system of meanings; their semantics is manifested in associative connections and word-formation potential of these words. The rest of the words are unambiguous, they have weak associative connections, they are not registered in dictionaries, there are no derivatives of these words or they are very limited in number (Rus. satin-satinovy, mango-mangovy, panda-pandovy).

Semantic limitations of most Sinicisms are connected with the sphere of their function, their relevance in speech of native speakers, and hence, the relevance of the reference in society. Many Russians still find some plants and animals (kumquat, badyan, mango, panda, Chow-Chow, etc.), sports and medical techniques (wushu, qigong), religious and philosophical views (Tao, Zen, Feng Shui) exotic. If the reference disappears, the word falls out of use and becomes obsolete (kaoliang, Honghuzi, chumiza (millet), chantung). Grammatical adaptation of Sinicisms depends on the properties of the reference and the word ending. The adjective pekoe (Rus. baikhovy) is fully assimilated grammatically; it has all the inherent adjectival grammatical meanings and forms. Russian nouns for orange, junk, pearls, book, panda, puer, Shar-Pei, Tai-ping, red guard, Honghuzi, and yuan also have grammatical indicators of gender, number, and case recorded in the national corpus.

Grammatical adaptation is not always consistent. For example, the names of dog breeds Chow-Chow, Shih Tzu, and Shar Pei are grammaticized to varying degrees: Shar Pei (Rus. declination forms Shar Peya, Shar Peiu, Shar Peiem, etc.) is complete, while ChowChow and Shih Tzu are non-declinable words. Full adaptation is 
hindered by the endings of the words, which do not allow the addition of the grammatical form of number and case. The names of writing Putonghua (national language) and Pinyin (transliteration of the Chinese language) do not have plural forms; they are not declined due to the abstract semantics of the words and the endings. The words naming abstract concepts are grammaticized; the lack of plural is explained by the nature of their semantics, which cannot be measured (Tao, Zen, Yin, Yang, Feng Shui). For names of food, the absence of the category of number is not unheard of in Russian (cf. Rus. shchi (soup), slivki (cream)); they name something that is measurable but could not be counted (buzy, dumplings, tofu, funchoza cellophane noodles). The word ketchup has the plural form ketchupy, which changes its meaning according to the rules of grammar: it acquires the meaning 'sort, kind' (cf. Rus. syr-syry (cheese-cheeses)). Names of plants such as badian, kaoliang, ginseng, lychee, mango, and chumiza (millet) in the Russian language do not change the number. If it is necessary to name the number, they would use a word combination two stars of badian/ two badians, 200 grams of kaoliang, three (roots) of ginseng, or five (pieces) mango. The word kumquat has the potential to change in numbers (Rus. forms kumquat - kumquaty - three kumquata); however, it does not occur in speech often, as this fruit is still exotic in Russia.

The words sateen and kaolin do not have the forms of number due to the peculiarities of semantics: they mean something that is measurable, but could not be counted. The word wok has no semantic and grammatical restrictions to be used in the plural (cf. Rus. wokwoky, skovoroda-skovorody (frying pan)); the absence of plural forms in this case is explained by the fact that it is used only in the professional speech of cooks; in the speech practice of most native speakers there are no situations in which the plural form would be in demand. The names of games and sports Mahjong, Wushu, kung $f u$, and medical practice qigong cannot change the numbers, which corresponds to the grammatical properties of this group of words in the Russian language (cf. Rus. box, lapta, gorelki). Thus, the grammatical adaptation of Sinicisms requires three conditions to be met: association with a certain lexical and semantic group, the word ending "convenient" for the Russian language, and demand in speech. These factors operate in the collective linguistic consciousness as a whole. Fully assimilated words (they comprise the majority of such words) meet these conditions. The Sinicisms that remained grammatically unadapted (wok, kumquat, Chow-Chow, Shih Tzu) do not meet some of these conditions.

All the words can be scaled according to their degree of assimilation. ${ }^{9,10}$ Sinicisms with the highest degree of assimilation are registered in dictionaries; they have no shade of novelty, they have the maximum frequency of use, they are regulated from the grammatical and spelling point of view, and they are actively used by the natives (orange, ketchup, pearls, book, manty (dumplings), and tea). A high degree of assimilation is typical of the words recorded in dictionaries, have a low coefficient of novelty, a high rate of word usage, and the correct contextual use (pekoe, ginseng, sateen). The medium degree of assimilation is typical of the Sinicisms recorded in dictionaries, with the average coefficient of novelty, often used in speech, either correctly or incorrectly (mango, wushu, yuan, yang). The words with a low degree of assimilation have appeared in the language, but had not yet been registered in dictionaries; they have low frequency of use and high degree of novelty (wok, oolong, funchoza cellophane noodles, Shar Pei).

Zero degree of assimilation characterizes the most recent borrowings in the language; they are not yet recorded by the dictionaries; otherwise, these are the words that have recently appeared and already outdated; they are not known by the natives and are not used in speech (buzy, kaoliang, Shantung, Tai-ping). O.S. Borisova suggests that when deciding on the distribution of the borrowed vocabulary according to the degree of assimilation, "it is advisable to rely on the indicators of the younger generation, as they form the modern speech usage". ${ }^{9-17}$

\section{Conclusions}

In the Russian language, borrowings are recorded in ancient sources from the earliest written period of the 11th century. The largest number of borrowed words and expressions come from the English language; borrowings from Chinese are insignificant in number; currently, the Russian speech practice includes 45 Sinicisms. The small number of borrowings is explained by the fact that the Russian and Chinese languages are of different structure, and this complicates the process of borrowing. Besides, the communication of the nations in different periods was limited for political and cultural reasons. From the point of view of the part of speech, almost all borrowings are nouns. Sinicisms in the Russian language are divided into eight thematic groups. Only four words (orange, pearl, book, tea) can be seen as fully assimilated by the Russian language; they have all grammatical forms, a developed system of lexical meanings, word-formation connections; they are used in phraseological units and paroemias. Sinicisms represent all the stages of the process of borrowing: from the zero level (Shar Pei, buza) to the middle (mango, yuan), then to the high (pekoe, ginseng, satin) and highest (pearls, book). In Russian, words are borrowed with the preservation of the features of pronunciation from the original language; their sound forms are actively adapted, though. The time of borrowing falls on the periods of close political, cultural, and economic contacts between the two nations. In the early middle ages, the Russian language borrowed from Chinese two words (book, pearls); most of the borrowings came later, in the late 20th-early $21^{\text {st }}$ centuries during the period of active political interaction between the two states. The analysis has showed that the full assimilation of the borrowed word requires centuries, provided that the denotation is demanded in the life of the people; therefore, the fate of the currently recorded Sinicisms in Russian depends on the further development of political, economic, and cultural relations between the two nations.

\section{Acknowledgments}

None.

\section{Conflicts of interest}

The authors declare that there is no conflict of interest.

\section{References}

1. Wei Iu, Proshchenkova NV. The Peculiarities of borrowing from Chinese in the Russia lexical system. Russia and China: history and prospects of cooperation. Materials YOU International Scientific and Practical Conference. 2017;577-580.

2. Yin Xu. A little bit about the Russian words of Chinese origin. 2018.

3. Dobrodomov IG. Borrowing. In: Iartseva VN, Editor. Linguistic Encyclopedic Dictionary. Moscow: Sovetskaya entsiklopediia. $1990 ; 158-259$.

4. Vasmer M. Etymology Dictionary. Moscow, Russia: Progress. 1986.

5. Shanskii NM, Ivanov VV, Shanskaia GV. Short etymology dictionary of the Russian language. Teacher's handbook. Moscow, Russia: Prosveshchenie. 1971. 
6. Oglezneva EA. Russian-Chinese pidgin: Experience of socio-linguistic description. Blagoveshchensk, Russia: AmGU. 2007;222.

7. Ozhegov SI, Shvedova NIu. Explanatory dictionary of Russian. Moscow, Russia: Azbukovnik. 1999

8. Marinova EV. Foreign words in the Russian speech of the late $20^{\text {th }}$-early $21^{\text {st }}$ centuries: Assimilation and usage. Moscow, Russia: Izd-vo "Elpis." 2008.

9. Borisova OS. Ways and sources of borrowing in Chinese. Al'manakh sovremennoi nauki i obrazovaniia. 2008;8(15):21-25.

10. Borisova OS. Adaptation of the foreign vocabulary in the language system (case study of the vocabulary of the late $19^{\text {th }}$-early $20^{\text {th }}$ century). Doctoral dissertation summary. Biisk, Russia. 2009.

11. Jiang Ying, Shipanovskaia LM. Russian borrowings in Chinese as a result of foreign language contacts. Filologicheskie nauki. Voprosy teorii i praktiki. 2016;7(1):144-152.

12. Kasymova OP, Gong Lei. Chinese borrowings in Russia (theme group of plant names). Vestnik Bashkirskogo universiteta. 2017a;22(4):1077-1081.
13. Kasymova OP, Gong Lei. Chinese borrowings in Russia (theme group of games and sports names). Materials IV International Scientific Practical Conference "Slavic ethnic groups, languages and cultures in the modern world. 2017b;189-195.

14. Krysin LP. Foreign word in the context of contemporary public life. In Zemskaya EA, Editors. Russkii iazyk kontsa XX stoletiia (1985-1995). Moscow, Russia: IaRK. 2000;142-161.

15. National Corpus of the Russian Language. 2018.

16. Perekhval'skaia EV. Dal'nevostochnyi variant. Formirovanie. Istoriia Struktura [Siberian pidgin (Far East variant)]. (Doctoral dissertation summary). St Petersburg, Russia. 2006.

17. Shipanovskaia LM, Jiang Ying. Lexical borrowings from Russian into Chinese: Historical aspect (case study of the Dictionary of Chinese Borrowings by Liu Zhengyan, Gao Mingkai, Mai Yongqian, Shi Yuwei). Theoretical and applied linguistics. 2016;2(2):112-123. 